\title{
De "capitães" e "pitboys": cartografias da marginalidade nas obras Capitães da Areia, do brasileiro Jorge Amado, e Marginais, do cabo-verdiano Evel Rocha
}

\author{
Of "captains" and "pitboys": cartographies \\ of marginality in Capitães da Areia, by the \\ Brazilian Jorge Amado, and Marginais, by the \\ Cape Verdean Evel Rocha
}

Érica ANTUNes Pereira*

RESUMO: AS OBRAS CAPITÃES DA AREIA, DO BRASILEIRO JORGE AMADO (1937), E MARGINAIS, DO CABO-VERDIANO EVEL ROCHA (2010), GUARDAM SEMELHANÇAS QUANTO AO TEMA DA VIOLÊNCIA E DA MARGINALIDADE, TENDO COMO VÍTIMAS CRIANÇAS E ADOLESCENTES. NESTE ARTIGO, PROCURO ESTABELECER ALGUNS PONTOS DE CONTATO ENTRE AS LITERATURAS DOS DOIS LADOS DO ATLÂNTICO, COM DESTAQUE PARA AS CARACTERÍSTICAS DAS PERSONAGENS E AS SITUAÇÕES SOCIAIS RETRATADAS NOS REFERIDOS ROMANCES.

ABSTRACT: THE WORKS CAPITÃES DA AREIA, BY THE BRAZILIAN WRITER JORGE AMADO (1937), AND MARGINAIS, BY THE CAPE-VERDEAN EVEL ROCHA (2010), HAVE SIMILARITIES CONCERNING THE ISSUES OF VIOLENCE AND MARGINALIZATION, WITH CHILDREN AND ADOLESCENTS AS VICTIMS. IN THIS PAPER, I ESTABLISH SOME POINTS OF CONTACT BETWEEN THE LITERATURES ON BOTH SIDES OF THE ATLANTIC OCEAN, EMPHASIZING THE CHARACTERS' TRAITS AND THE SOCIAL SITUATION DEPICTED ON BOTH NOVELS.

PALAVRAS-CHAVE: ESTUDOS COMPARADOS; LITERATURA BRASILEIRA; LITERATURA CABO-VERDIANA. KEYWORDS: COMPARED STUDIES; BRAZIILAN LITERATURE; CAPE-VERDEAN LITERATURE.

\footnotetext{
* Pós-doutoranda na Universidade de São Paulo, com bolsa da Fundação de Amparo à Pesquisa do Estado de São Paulo, São Paulo, São Paulo, Brasil. Supervisão da Profa. Doutora Simone Caputo Gomes. E-mail: erica.antunes@gmail.com.
} 
Em casa

de menino de rua

o último a dormir

apaga a lua.

(Giovani Baffô)

2012, Jorge Amado completaria cem anos de idade. Tinha ele apenas vinte e cinco quando publicou a obra Capitães da Areia. Em 1937, a literatura brasileira vivia o auge do chamado Regionalismo de 30, despontado em 1928 com A bagaceira, de José Américo de Almeida, logo seguido de obras como $O$ Quinze (1930), de Rachel de Queiroz, São Bernardo (1934) e Vidas secas (1938), de Graciliano Ramos, Bangüê (1934), de José Lins do Rego, Caminhos cruzados (1935), de Erico Veríssimo, Mar morto (1936) e Capitães da Areia (1937), de Jorge Amado.

Um ano antes de Capitães da Areia, em 1936, era publicado, em Cabo Verde - país formado por dez ilhas, num total de $4.033 \mathrm{~km}^{2}$, localizado a cerca de 450 $\mathrm{km}$ da costa africana e independente de Portugal em 05 de julho de 1975 -, o primeiro dos nove números da Revista Claridade, organizada por Baltasar Lopes, Jorge Barbosa e Manuel Lopes, escritores de reconhecida envergadura na série literária do arquipélago que muito "beberam" da literatura brasileira, com destaque para o referido Regionalismo de 1930. Trata-se de uma geração que, segundo Simone Caputo Gomes (2008, p. 113), "preferiu imaginar-se não mais à luz do modelo colonizador ou de uma literatura colonial apologética da figura do herói navegador, e escolheu mirar-se em outro paradigma cultural, forte, irmão, independente: o Brasil dos mulatos, malandros e heróis ignorados".

Nesse diálogo estabelecido, podemos afirmar que a obra de Jorge Amado tenha sido uma das vias que mais favoreceram o referido processo de identificação dos autores cabo-verdianos com o Brasil, considerado então uma espécie de "irmão mais velho" cujo sistema literário, já solidificado nos termos propostos por Antonio Candido (1997, p. 15), tornou-se alvo de interesse por simbolizar a ruptura cultural e política com o império português.

As razões do interesse dos cabo-verdianos pelo nosso escritor baiano ou, antes, pela produção literária dele podem ser as mais diversas, mas cremos que a maior decorra da proximidade com a vida cotidiana e as gentes do 
povo, representadas, entre outros, por pescadores ${ }^{1}$, meninos de rua, lavadeiras, prostitutas, cachaceiros, proxenetas, estivadores, trabalhadores da terra, vagabundos, mães e pais de santo, enfim, os marginalizados e excluídos da sociedade que, na pena de Jorge Amado, ganham vez e voz, sendo-lhes ressaltados/representados os pensamentos e a sede de justiça social.

Setenta e três anos após a publicação de Capitães da Areia no Brasil, ou seja, em 2010, estava eu na cidade da Praia, capital de Cabo Verde, mais especificamente nos corredores do armazém da Biblioteca Nacional, em busca de obras e autores contemporâneos para o projeto que hoje desenvolvo em nível de pós-doutorado, e, de repente, um título me chamou a atenção: Estátuas de Sal (2003), do cabo-verdiano Evel Rocha ${ }^{2}$. Inicialmente, imaginei tratar-se de uma releitura da bíblica história de Ló (Gênesis 19), homem que teria sido poupado por Deus da destruição ocorrida em Sodoma e Gomorra com a condição de que fugisse com a família sem que olhassem para trás, no que não foi obedecido pela mulher, transformando-se esta em uma estátua de sal. Em Estátuas de Sal, no entanto, Evel Rocha traz à tona o cotidiano de uma família da Ilha do $\mathrm{Sal}^{3}$, relembrado pela memória de Adalberto Delgado, que retorna à terra natal depois de dezoito anos de emigração, e o diálogo simbólico com a saga bíblica se opera principalmente porque a obra cabo-verdiana trata de temas contundentes para a sociedade crioula (impactando, por consequência, a literatura do arquipélago), como o homoerotismo (próximo da imagem negativa das cidades de Sodoma e Gomorra) e a pulverização dos laços familiares marcados pelo patriarcado.

1. A atividade pesqueira, em Cabo Verde, país arquipelágico banhado pelo Oceano Atlântico, é intensa, daí a forte identificação com a imagem dos pescadores.

2. Naquela ocasião, trouxe também um exemplar para a Profa. Doutora Simone Caputo Gomes, que, verificando a pertinência da obra para a pesquisa em nível de Mestrado de Maurício Oliveira Rios, seu então orientando na Universidade de São Paulo, indicou-lhe a leitura, do que resultou a dissertação Literatura cabo-verdiana e discussão de gênero: propostas para masculinidades e feminilidades em obras de Evel Rocha, Germano Almeida e Dina Salústio, defendida em 18 de abril de 2012.

3. A Ilha do Sal pertence ao grupo do Barlavento cabo-verdiano e, apesar de ser uma das menores do país, tem reconhecimento internacional graças ao turismo bastante desenvolvido. 
Mas foi ao ler Marginais ${ }^{4}$, obra publicada exatamente em 2010 (sete anos após Estátuas de Sal) e a terceira de Evel Rocha (a primeira foi Versos d'Alma, em 1997), que as relações intertextuais com o Brasil se apresentaram: é um romance que, pelo teor temático, certamente constitui um marco da literatura de Cabo Verde, e, tal qual em Capitães da Areia, tem meninos abandonados e/ ou marginalizados pela sociedade como personagens principais.

$\mathrm{Na}$ obra cabo-verdiana, porém, diferentemente do que se verifica no romance brasileiro, a narrativa se passa em primeira pessoa: Sérgio Pitboy, um adolescente cuja vivência se dá à revelia da família (destroçada pelo alcoolismo e abandono paternos e pela emigração materna), assume a voz para denunciar as diferenças sociais e, por consequência, desmascarar qualquer tentativa de idealização da sociedade cabo-verdiana, marcada, na obra, por injustiças e violências físicas e/ou psicológicas que conduzem, com raras exceções, ao pessimismo e ao determinismo.

Nesse momento, lembro a definição de Gayatri Spivak a respeito dos sujeitos subalternos, considerados aqueles pertencentes "às camadas mais baixas da sociedade constituídas pelos modos específicos de exclusão dos mercados, da representação política e legal, e da possibilidade de se tornarem membros plenos no estrato social dominante" (SPIVAK, 2010, p. 12), caso dos Capitães da Areia, na obra homônima, e dos Pitboys, em Marginais. Para a referida teórica, no célebre e contundente ensaio Pode o subalterno falar?, a fala do subalterno não deve estar condicionada ao discurso dominante, ou seja, não basta querer doar-lhe voz ou falar por ele, é preciso abrir espaço para que ele se expresse.

Trata-se, entretanto, de um dilema cuja solução parece impossível, a não ser que consideremos - o que faço neste momento - o campo da representação como um cenário que viabiliza o conhecimento do Outro, ou seja, do subalterno. De qualquer forma, não é a sua voz que fala ou é invocada, mas sim a expressão de um horizonte marginalizado pela experiência dominadora e que, ao materializar-se em texto, de alguma forma efetiva um resgate a me-

4. Depois de ler Estátuas de Sal, consegui contato com o autor, perguntei-lhe sobre novas obras e soube da então recente publicação de Marginais. Evel Rocha gentilmente enviou-me, a meu pedido, dois exemplares: um para mim e outro para Simone Caputo Gomes. Tal intercâmbio se ramificou e, hoje, a obra tem sido lida e estudada, na Universidade de São Paulo, por alunos de graduação, pós-graduação e pesquisadores, com destaque para Mário César Lugarinho, que focalizou o romance Marginais em sua tese de livre docência defendida neste ano de 2012. 
mórias e histórias pretensamente ocultas e/ou apagadas. Como afirmei, não é a voz do subalterno a falar, mas sim a encenação de uma voz que se quer dele.

Nesse sentido, se pensarmos o caso de Capitães da Areia e Marginais, especificamente, perceberemos que o tema, voltado para a vivência dos meninos de rua postos à margem pela sociedade, aproxima-os do leitor. No romance cabo-verdiano, instala-se também uma espécie de curiosidade empática à medida que a narrativa é feita em primeira pessoa, mas concomitantemente ocorre uma matização desse processo identificatório pelo fato de haver um intermediário entre Sérgio Pitboy e o leitor. Surge, assim, logo nas primeiras páginas, a figura de um fictício apresentador da obra, representada por um antigo colega de liceu a quem o narrador teria entregado uma espécie de diário com sua história de vida e que, entretanto, manifesta superioridade conforme retrata o narrador-personagem a lhe chamar de "senhor" e deixa clara a sua profissão (é engenheiro), fatos delimitadores de duas posições sociais opostas e suficientes para torná-los praticamente dois estranhos entre si.

Nas duas obras, a marginalidade social é focalizada a partir da experiência das personagens enquanto participantes de grupos formados por crianças e adolescentes que, desprovidos da proteção familiar, lutam pela sobrevivência e, para tanto, às vezes agem ilicitamente, contrariando comportamentos considerados morais e desejáveis pela comunidade. Assim, os Capitães da Areia eram

crianças abandonadas que viviam do furto. Nunca ninguém soube o número exato de meninos que assim viviam. Eram bem uns cem e destes mais de quarenta dormiam nas ruínas do velho trapiche.

Vestidos de farrapos, sujos, semiesfomeados, agressivos, soltando palavrões e fumando pontas de cigarro, eram, em verdade, os donos da cidade, os que a conheciam totalmente, os que totalmente a amavam, os seus poetas (AMADO, 2008, p. 29).

Diferentemente dos Capitães da Areia, a maioria dos Pitboys, grupo que ocupa as páginas de Marginais, frequentava a escola, fato, todavia, não bastante para configurar uma expressiva diminuição da marginalidade: a gênese desta, na obra de Evel Rocha, está na desconfiguração dos laços familiares decorrente do alcoolismo, da pobreza, da emigração, do abandono, da violência, dentre outros (re)conhecidos problemas enfrentados pela sociedade 
cabo-verdiana. O número de meninos que compunham os Pitboys é muito menor que o dos Capitães da Areia, apenas dez, o que se justifica pelo espaço de inserção diegética: Espargos, a maior localidade da Ilha do Sal, tem cerca de 21 mil habitantes na atualidade, muito diferente da Salvador do final da década de 1930, cuja população já rondava os 290 mil. Quanto à atuação dos Pitboys, logo percebemos que, pela descrição de Sérgio, o protagonista, muito se aproxima do comportamento dos Capitães da Areia:

Embrenhávamo-nos pela noite como cães vadios, apoderávamo-nos dos carros estacionados à porta do cinema, surripiávamos tudo o que estivesse mal guardado e, aos poucos, o nosso grupo foi engrossando até sermos dez rapazes adolescentes a quem as pessoas passaram a chamar de Pitboys (ROCHA, 2010, p. 27).

O grupo, para os adolescentes representados em Capitães da Areia e em Marginais, é um espaço para a formação de identidades ou "identificações em curso" (SANTOS, 2000, p. 135) que possibilitam a experiência e o exercício impositivo da voz e da força advindas da união dos pares, o que garante alguma segurança e, concomitantemente, o reconhecimento da individualidade. No romance cabo-verdiano, o narrador afirma:

Pertencer aos Pitboys era o mesmo que receber um certificado de emancipação à repressão dos pais e dos adultos que nos rodeavam; era uma forma de defender a nossa integridade, onde expúnhamos a nossa cólera sem medo dos outros, onde enunciávamos toda a nossa crueldade de modo a nos vingarmos da rejeição social. Toda a nossa revolta tinha apenas um alvo: a intolerância. No seio do grupo o medo ficava de fora. Ninguém, enquanto estivesse no grupo, deveria demonstrar qualquer sinal de fraqueza. O choro, a submissão e o medo eram sinais de fraqueza e nenhum de nós estava na disposição de passar por afronta. Era necessário encarar o perigo com desprezo e cuspir na cara do medo, era necessário demonstrar revolta por tudo o que fosse regra e bom comportamento, pois, as pessoas olhavam-nos com desprezo e devíamos retribuir-lhes desprezo também (ROCHA, 2010, p. 29).

Essa descrição de pertencimento muito se aproxima do conceito francês da galère, considerada por François Dubet (1987) uma "experiência de vida" 
que tem como características sociabilidade solta, niilismo, autodestrutividade e raiva, levando a "pequenas incivilidades", como atividades criminais intermitentes, transitórias e de pequena gravidade. Por outro lado, considerando que a delinquência da galère é, ainda de acordo com Dubet, não organizada, ou seja, não advinda de uma rede estável que propicia a formação de uma identidade comum, o grupo dos Pitboys mais se aproxima do conceito de gangue nos moldes propostos por Carla Coelho de Andrade, para quem

as gangues que marcam sua presença no nosso cenário urbano, ao contrário das gangs estadunidenses, não conduzem negócios com características empresariais. Geralmente têm, como as gangs, uma demarcação territorial, liderança definida, interação recorrente e engajamento em comportamento violento como práticas fundamentais de estruturação distintiva, mas não objetivam exatamente assegurarem aos seus integrantes um meio de vida permanente, com possibilidade de mobilidade social pelos ganhos advindos de práticas delinquentes e ilícitas. [...] Embora se distanciem do modelo difuso de sociabilidade da galère descrito por Dubet, há na 'experiência de vida' desses jovens algo que os aproxima: a desmotivação com a escola, a perda de sentido do trabalho, o sentimento de serem estigmatizados por serem pobres e viverem em locais relegados, uma certa revolta diante das desigualdades sociais e a transformação do ócio [...] em uma violência tornada corriqueira e banal (ANDRADE, 2007, p. 23-24).

Em Capitães da Areia, os objetivos do grupo não são descritos sob o ponto de vista dos meninos, mas por meio de uma das notícias de jornal que dão início à narrativa; no caso, logo na primeira, intitulada "Crianças ladronas", podemos ler:

Esse bando que vive da rapina se compõe, pelo que se sabe, de um número superior a cem crianças das mais diversas idades, indo desde os oito aos dezesseis anos. Crianças que, naturalmente devido ao desprezo dado à sua educação por pais pouco servidos de sentimentos cristãos, se entregaram no verdor dos anos a uma vida criminosa. São chamados de Capitães da Areia porque o cais é o seu quartel-general. E têm por comandante um molecote dos seus catorze anos, que é o mais terrível de todos, não só ladrão, como já autor de um crime de ferimentos graves, praticado na tarde de ontem. Infelizmente a identidade deste chefe é desconhecida (AMADO, 2008, p. 11). 
Como podemos observar, tanto os Capitães da Areia quanto os Pitboys têm a educação como um pretenso ponto de equilíbrio rompido pelo desfacelamento do núcleo familiar. Além disso, a noção de grupo é imperativa para a existência de um sentimento de pertença, ainda que à margem da sociedade, daí decorrendo os pequenos furtos - em Cabo Verde, chamados de "caçubody", uma corruptela de "cash or body" - e a necessidade de se fazerem temer pela violência física e/ou psicológica.

Retomando o conceito de Carla Coelho de Andrade acerca das gangues, no caso das obras em tela, a "possibilidade de mobilidade social" é praticamente irrisória, pois em ambas permeia uma atmosfera de determinismo que torna quase impossível acenar para qualquer modificação social favorável às personagens. Em Capitães da Areia, ela só é alcançada por Professor, que, graças ao seu talento como desenhista e pintor, ganha o mundo apresentando telas que tematizam a vida dos antigos companheiros: o apelido já não o acompanha, passa a ser João José, um artista admirado e reconhecido (AMADO, 2008, p. 252). Outro "capitão" que escapa ao destino das ruas é Pirulito, que, movido por fervorosa fé, segue o caminho da religião e, despido do antigo apelido, torna-se o irmão Francisco da Sagrada Família (AMADO, 2008, p. 232-234). Já em Marginais, é Jorginho, salvo pelo futebol, o "pitboy" que tem a sorte de mudar de vida: foi contratado para jogar em Portugal (ROCHA, 2010, p. 82, 126-128) e, no time, passou a ser Da Silva.

É curioso que as três únicas personagens que tiveram a oportunidade de progredir no extrato social assumam os nomes próprios em detrimento dos apelidos, o que caracteriza, numa espécie de rito de passagem da subalternidade para a dominação, a (trans)formação dessas identidades, que, entretanto, permanecem sempre em trânsito, já que dos antigos companheiros não se esquecem: seja ao imprimir-lhes a imagem na tela, ao proferir orações ou ao comemorar um gol, lá estão eles presentes, materializados pela memória de Professor ou João José, de Pirulito ou irmão Francisco da Sagrada Família e de Jorginho ou Da Silva.

Excetuando esses três casos, todas as outras personagens, quer do romance brasileiro, quer do cabo-verdiano, permanecem num limbo que podemos chamar de marginalidade, numa reafirmação determinista posta em evidência, na obra de Evel Rocha, por Sérgio Pitboy: 
[...] faltava ambição porque deixámos de acreditar nos outros e em nós mesmos, acomodámo-nos à nossa condição de gente sem eira nem beira, no nosso casulo do conformismo e na nossa sina de "filhos de um deus menor". Tornámo-nos indolentes, enveredámos pela cultura dos miseráveis, aceitámos o credo imposto que o melhor era lutar pelo pão de cada dia e, se não houvesse, benzer a boca antes de dormir. Porém, eu, nós, os da geração rasca, os marginalizados da periferia, rejeitamos em absoluto essa condição a que os nossos pais foram relegados e somos forçados a enveredar para um caminho totalmente contrário, porém arriscado e perverso: o caminho da delinquência (ROCHA, 2010, p. 89).

A delinquência, portanto, é tomada como uma forma de rebelião ao determinismo social que, consoante Émile Durkheim, em seu texto O que éfato social? (1978), decorre da impossibilidade de o indivíduo explicar a sociedade, sendo esta, em verdade, que o explica. De acordo com o referido cientista social considerado um dos fundadores da Sociologia, para se caracterizar um fato social são necessárias três características: generalidade, exterioridade e coercitividade. Em outras palavras, o que as pessoas sentem, pensam ou fazem, independente de suas vontades individuais, é um comportamento estabelecido pela sociedade; não é algo que seja imposto especificamente a alguém, é algo que já existia antes e que continua depois, sem dar margem a escolhas.

Jorge Amado se mostra atento à questão determinista à medida que, no episódio em que Pedro Bala, o chefe dos Capitães da Areia, segue para o reformatório, onde passa pelas mais terríveis privações, entre maus tratos físicos e psicológicos, e tem sua personalidade e aparência dissecadas pelo diretor: "[...] Veja... O tipo do criminoso nato. É verdade que você não leu Lombroso... Mas se lesse, conheceria. Traz todos os estigmas do crime na face. Com esta idade já tem uma cicatriz. Espie os olhos... Não pode ser tratado como um qualquer. Vamos lhe dar honras especiais..." (AMADO, 2008, p. 202).

Para o médico italiano Cesare Lombroso - invocado não por acaso na obra de Jorge Amado, que se formou em Direito -, a etiologia do crime é eminentemente individual e deve ser buscada no estudo do delinquente. Assim, a sua teoria do "delinquente nato", expressa na obra O bomem delinquente (2007) e segundo a qual as características físicas, fisiológicas e mentais dos indivíduos demonstram se são predispostos ao crime ou não, aproxima-o, pelo viés biológico, do determinismo. 
Tanto o determinismo social quanto o biológico, entretanto, são postos em xeque, nas obras de Jorge Amado e Evel Rocha, não porque três personagens, como nos reportamos há pouco, escaparam das teias da marginalidade, e sim exatamente pelo seu contrário, ou seja, porque a maioria dos meninos se afunda num conceito de grupo que lhes possibilita subverter a ordem e rebelar-se contra os que consideram socialmente nocivos, caso da polícia, no episódio em que os policiais são ludibriados por Pedro Bala quando este, com a ajuda dos outros Capitães da Areia, invade a delegacia a fim de resgatar o Ogum apreendido de um terreiro de candomblé (AMADO, 2008, p. 96109), e, também, do advogado Apolinário, que, conhecido pelo seu prazer mórbido de destratar os menos validos, em especial o protagonista, tem uma perna quebrada e escoriações decorrentes de um acidente automobilístico provocado pelos Pitboys (ROCHA, 2010, p. 109-111). Melhor explicando, tais estratégias reativas conduzem à inversão da ordem por aqueles até então considerados subalternos: estes, quando se veem impedidos de fazer da palavra a sua arma, agem. A ação é, assim, uma espécie de grito primevo para a conquista de novos espaços e para a assunção de novas identidades.

Além da constituição de grupo, outra forma de ação emprestada à rasura do espaço do dominador é a sexualidade, que, em Capitães da Areia e em Marginais, apresenta-se naturalizada e oscila entre a violência e a afetividade. Assim, nas duas narrativas, observamos casos de abuso sexual (AMADO, 2008, p. 89-95; ROCHA, 2010, p. 157-158) e de pedofilia (AMADO, 2008, p. 45; ROCHA, 2010, p. 88-89), mas também de carinho e amor (AMADO, 2008, p. 192-193; ROCHA, 2010, p. 23, 30-31). A respeito da percepção sexual dos Pitboys, ilustrativa é a seguinte passagem:

Foi no grupo que aprendi os detalhes sórdidos sobre a vida debaixo de um lençol, onde soube das mil e uma utilidades da camisinha e passei a conhecer a lista dos homens e das mulheres mais cornudos da ilha. Beto contava de olhos fechados as horas e os dias em que os pares se fundiam em abraços libidinosos, sabia a hora em que as marias eram desvirginadas, o delicioso instante em que os rapazes pulavam a cerca dos currais de Alto Santa Cruz para os encontros prazerosos com as alimárias em reboliço. Não via pecado nenhum nessas promiscuidades, pois, as risadas maldosas dos adolescentes projectavam-se na vontade de trancar numa cabra, numa besta ou numa vaca sonolenta (ROCHA, 2008, p. 27). 
Como podemos perceber, o grupo, mais uma vez, é a referência na formação do protagonista e dos demais adolescentes que constituem os Pitboys, o mesmo ocorrendo com os Capitães da Areia, como comprova este trecho:

Para que tinha vindo de noite, para que se arriscara na areia do cais? Não sabia que a areia das docas é a cama de amor de todos os malandros, de todos os ladrões, de todos os marítimos, de todos os Capitães da Areia, de todos os que não podem pagar mulher e têm sede de um corpo na cidade santa da Bahia? [...] Pedro Bala também só tinha quinze anos, mas há muito tempo conhecia não só o areal e os seus segredos, como os segredos do amor das mulheres. Porque se os homens conhecem esses segredos muito antes que as mulheres, os Capitães da Areia os conheciam muito antes que qualquer homem (AMADO, 2008, p. 90-91).

Nas duas obras, as relações homoeróticas são retratadas de modo enfático, como a quebrar tabus em sociedades tão conservadoras, como a brasileira e a cabo-verdiana. Se, em tempos de "Paradas Gays" com milhares de pessoas entre assistentes e participantes, como todos os anos vemos desfilar na Av. Paulista, em São Paulo, permanece ainda a luta pelo direito à liberdade sexual (embora sua garantia esteja presente no ordenamento jurídico brasileiro), o que então imaginar do ano de 1937, quando foi publicado Capitães da Areia?

Em Cabo Verde, pelo que pude abstrair das vezes em que lá estive e de conversas com as mais diferentes personalidades, a situação se mostra tão ruim ou ainda pior, pois não há sequer o amparo de um "Gay Day", simbolicamente tão necessário para o posicionamento em prol da emancipação sexual.

É fato, pois, que os dois lados do Atlântico ainda atravessam uma conturbada tempestade quando o tema se volta para as relações homoeróticas, mas nem por isso Jorge Amado e Evel Rocha deixaram de navegar as águas turbulentas, escrevendo, com um leme feito de tinta, as páginas de uma história que precisa e merece ser urgentemente desbravada. Ganham vida, então, personagens como os "capitães" Boa-Vida, Barandão e Almiro, e como os "marginais" Valdomiro/Mirinha, Lena, Alcindo, Sérgio e Fusco, que (man) têm experiências homoeróticas ao longo das duas narrativas.

Apesar de ser retratado de forma naturalizada nos dois romances, o homoerotismo é visto como pecado e/ou doença pela sociedade dominadora, fato 
que não passa despercebido aos autores ao descreverem cenas como esta, de Capitães da Areia, que agora destaco:

Padre José Pedro achava que Deus perdoaria e queria ajudá-los. [...] Fora mesmo ele um dos que mais concorreram para exterminar a pederastia no grupo. [...] Enquanto ele lhes disse que era necessário acabar com aquilo porque era um pecado, uma coisa imoral e feia, os meninos riram nas suas costas e continuaram a dormir com os mais novos e bonitos. Mas no dia em que o padre, desta vez ajudado pelo Querido-de-Deus, afirmou que aquilo era coisa indigna num homem, fazia um homem igual a uma mulher, pior que uma mulher, Pedro Bala tomou medidas violentas, expulsou os passivos do grupo. [...] Por assim dizer, Pedro Bala arrancou a pederastia de entre os Capitães da Areia como um médico arranca um apêndice doente do corpo de um homem (AMADO, 2008, p. 112-113).

Em Marginais, a cena é ainda mais contundente e chega às raias do grotesco, pois a personagem Fusco é submetida a uma "terapia por aversão", tratamento consistente no incentivo à excitação seguido de choque elétrico nas nádegas, sob a justificativa de que "inibe a vontade, desencoraja e ajuda a perder o hábito" (ROCHA, 2010, p. 80), tudo dotado de um suposto profissionalismo medicinal, como comprova o seguimento que passo a reproduzir:

Assim que o doutor Melício soube da condição feminina de Fusco, disse que era capaz de reabilitá-lo. O médico marcou-lhe o primeiro encontro no seu consultório e depois de uma conversa amistosa e florida, o médico disse-lhe que o tratamento era uma terapia para inibir o desejo homossexual. Parece um tanto ou quanto complicado, mas é muito simples. A terapia exige força de vontade e em pouco tempo estarás desfrutando o gozo de ter no teu ombro o cheiro do perfume das mocinhas de Espargos (ROCHA, 2010, p. 79-80).

A questão homoerótica é abordada muito mais profundamente em Marginais que em Capitães da Areia: enquanto na obra brasileira as relações entre os meninos se apresentam de forma tímida, limitadas a breves descrições de carinho (AMADO, 2008, p. 40-41, 47), no romance cabo-verdiano a homoafetividade é minuciosamente apresentada, sendo retratados, inclusive, casos de travestismo e de hermafroditismo, como o de Loiro, que 
era um verdadeiro playboy de pé rapado, um xavequeiro da primeira água, até o dia em que fomos surpreendidos com a notícia que dava conta que ele, ou melhor ela estava grávida. [...] A situação ficou esclarecida quando descobriram que ele era macho e fêmea. [...] Alcindo era um casal tipo "dois em um" como nos produtos do mercado em promoção? A Natureza, na sua infinita perfeição criou o hipopótamo, o animal mais feio do mundo. Por que haveria de criar um Alcindo, perfeito exemplo de feiura que não era nem homem nem mulher, um legítimo representante dos dois sexos? (ROCHA, 2010, p. 122-123)

No entanto, embora rasurem o padrão comportamental imprimido pelas sociedades brasileira e cabo-verdiana, as obras de Jorge Amado e Evel Rocha ainda carregam consigo alguma dificuldade para lidar com o tema do homoerotismo, o que pode ser comprovado pelo fim que as personagens gays assumem, quase sempre trágicos. Dessa forma, em Capitães da Areia, Almiro, cuja aparição, no decorrer da narrativa, liga-se à prática de relações homoeróticas, apanha varíola (vulgarmente conhecida como alastrim) e morre em decorrência da doença (AMADO, 2008, p. 144-150, 158). Em Marginais, por sua vez, embora as personagens, tal qual ocorre em Capitães da Areia, também tenham fins arrasadores, há um ensaio de reviravolta à medida que, de alguma forma, elas deixam a sua marca para a sociedade. Assim, ainda que Valdomiro tenha morrido em decorrência de uma overdose por cocaína, não sai de cena sem antes gravar na memória dos sobreviventes a rejeição paterna, o que fica visível quando uma carta a este endereçada é trazida à tona:

Sou homensexual, a sujeira que entrou na sua casa mas não sei viver de outra maneira. Quero que saibas que eu não virei homensexual, nasci assim. Por isso, meu pai, para que não sintas mais humilhação e porque não sei viver de outra maneira, vou matar a cabeça. Talvez num outro mundo eu possa ser mais compreendido tal como sou. Sou capaz de aguentar as troças, a fofoca da vizinhança, mas não posso viver sem a tua bênção! Perdoa-me por ter nascido gay. Adeus para sempre (ROCHA, 2010, p. 118).

Interessante é o termo "homensexual", que, sintetizando os conceitos e as definições emprestadas às palavras "homem", "homossexual" e "sexual", alegoriza a extensão da briga interior vivenciada por Valdomiro em sua curta 
existência. Sérgio, o protagonista, que teve sua "primeira experiência sexual com Valdomiro" (ROCHA, 2010, p. 116), também morre com um corte no pulso (suicídio, muito embora já estivesse condenado pela tuberculose), mas, em contrapartida, deixa sua história de vida - materializada no diário e posteriormente convertida e publicada em livro - como um legado às gerações futuras. A escrita, como podemos comprovar, continua sendo a arma para lutar pelos próprios direitos e pela formação de uma sociedade movida pelos sensos de justiça e de equidade.

Uma personagem, porém, não morre, mas mesmo assim tem seu paradeiro indefinido ao fim de Marginais: é Fusco, que

embarcou num iate e ninguém sabe o que foi feito dele. Provavelmente, estará gozando a vida com algum amante pelos mares do sul, cortando as ondas majestosas e brancas dos seus sonhos de infância. Torço para que sejas feliz do teu jeito, que sejas a mulher que a natureza defraudou, que consigas rebolar sem complexos, que sintas liberto dos preconceitos, que obtenhas aqueles longos e fartos seios com que sempre sonhaste, que desfiles em alguma manifestação envolto numa bandeira gay, travestido de mulher com longas pestanas e botas até o joelho como sempre sonhaste, que vivas em plenitude a tua homossexualidade, nas ruas de Sidney, em algum cabaré de Amesterdão, mas vivas até morrer! (ROCHA, 2010, p. 208-209)

Do excerto, entrevemos um quase sôfrego desejo do narrador de que Fusco tenha resistido às intempéries sociais e, por consequência, possa viver livremente os sonhos acalentados durante toda a vida. É uma esperança que se consuma a partir de outra esperança, numa terrível sequência condicional: "se" Fusco viver, "se" driblar os preconceitos, "se" derrubar as barreiras da marginalidade, "se" alcançar a liberdade sexual e de pensamento, aí então poderá ser feliz.

Trata-se de um futuro que, apesar de perseguido, continua incerto. Até alcançá-lo e torná-lo realidade, muitos "Capitães da Areia" e "Pitboys" terão de continuar sua jornada, dia após dia, contra a exclusão social, o que só é possível por meio da reiterada efervescência coletiva demonstrativa da rebeldia e da força marginalizada. Ao se unirem, esses meninos e meninas garantem a própria sobrevivência, que representa, metaforicamente, a reconstrução familiar. 
Ratificando esta imagem, e já em vias de encerramento, retomo os versos de Giovani Baffô, que, em epígrafe, abrem o presente texto, para lembrar que a lua, símbolo da renovação e da transformação, está num teto cujo limite é o infinito e, embora não tenha luz própria, brilha ao refletir a alheia. Assim também as personagens de Capitães da Areia e Marginais: renegadas à marginalização, espelham uma sociedade incapaz de enxergar a própria sombra; no entanto, desse mesmo meio opressivo e destrutivo de sonhos, é possível, ainda, extrair poesia.

\section{Referências bibliográficas}

AMADO, Jorge. Capitães da areia. São Paulo: Companhia das Letras, 2008.

ANDRADE, Carla Coelho de. Entre gangues e galeras: juventude, violência e sociabilidade na periferia do Distrito Federal. Tese (Doutorado em Antropologia Social). Universidade de Brasília, Brasília, 2007.

CANDIDO, Antonio. Iniciação à Literatura Brasileira. São Paulo: Humanitas, 1997.

DUBET, François. La Galère: jeunes en survie. Paris: Fayard, 1987.

DURKHEIM, Émile. O que é fato social? In: As regras do método sociológico. Coleção Os Pensadores. São Paulo: Abril Cultural, 1978.

GOMES, Simone Caputo. Cabo Verde: literatura em chão de cultura. Cotia: Ateliê Editorial-UNEMAT; Praia: Instituto da Biblioteca Nacional e do Livro, 2008.

LOMBROSO, Cesare. O homem delinquente. Trad. Sebastião José Roque. São Paulo: Ícone, 2007.

ROCHA, Evel. Estátuas de sal. Mindelo: Ilhéu, 2003. . Marginais. Praia: Edição do Autor, 2010.

SANTOS, Boaventura de Sousa. Pela mão de Alice: o social e o político na pós-modernidade. São Paulo: Cortez, 2000.

SPIVAK, Gayatri Chakravorty. Pode o subalterno falar? Trad. Sandra Regina Goulart Almeida; Marcos Pereira Feitosa; André Pereira. Belo Horizonte: Editora da UFMG, 2010 .

Recebido em 11 de julho e aprovado em 07 de outubro de 2012. 